\title{
Investigation of the Protective Capacities of Precipitation-Hardening Stainless Steels in terms of Charged and un-Charged Particle Radiation
}

\author{
Erdem ŞAKAR ${ }^{1 *}$
}

\begin{abstract}
In this study, it has been focused on the investigation of particle-shielding performances of precipitation-hardening stainless steels (PH-SSs). In line with this focus, the stopping powers and ranges values of four different $\mathrm{PH}-\mathrm{SSs}(15-5 \mathrm{PH}, 15-7 \mathrm{PH}, 17-4 \mathrm{PH}$ and 17-7PH) for energetic charged particles (proton, electron and alpha particles) were carried out in the kinetic energy range of 0.01-20 $\mathrm{MeV}$. In addition, the fast neutron removal cross-section values of PH-SSs examined for neutrons were calculated at 4.5 MeV. In order to achieve a remarkable conclusion about the particle-absorbing capacities of the PH-SSs investigated, all calculations were also performed for some concretes (steelmagnetite, steel-scrap and ordinary concretes) used as shielding materials in nuclear applications. The results obtained were comparatively presented as a function of kinetic energy of particles. In addition, the results obtained were evaluated in terms of both types of particle and phase structures of materials examined. According to the results obtained, it was observed that the all investigated parameters are independent of phase structures of PH-SSs, that the all calculated parameters for PH-SSs examined are very close to each other, and that the particle-shielding performances of PH-SSs under examination are better than comparison concretes. As a result of the data obtained from this study, it was observed that $\mathrm{PH}-\mathrm{SSs}$ can be used as an alternative material in areas where particle radiation safety is required because of their superior characteristic and shielding properties.
\end{abstract}

Keywords: Stopping power, range, fast neutron removal cross-section, particle shielding, stainless steel.

Erdem ŞAKAR (Orcid ID: 0000-0002-1359-4464), Faculty of Sciences, Department of Physics, Atatürk University, Erzurum, Turkey

Corresponding Author: Erdem ŞAKAR, e-mail: erdem@atauni.edu.tr

Geliş tarihi / Received: 30-10-2019

Kabul tarihi / Accepted: 28-11-2019 


\section{INTRODUCTION}

Iron and its commonly used alloys are relatively weak materials in terms of many application. Because these materials deform and lose their characteristic properties in air, rust, acids and furnace atmospheres and thus the material becomes unusable in time. In spite of these materials, iron-chromiumnickel alloy group, which are non-corrode in seawater, resistant to concentrated acids and nondeformable up to temperature of about $1100{ }^{\circ} \mathrm{C}$, has been developed and named as stainless steel. The stainless steels (SSs) are considered as technologically and industrially important materials because of their almost endless number usage. The SSs can be categorized traditionally into six groups: ferritic, austenitic, ferritic-austenitic, martensitic, martensitic-austenitic and precipitation hardening $(\mathrm{PH})$ stainless steels (Alım et al., 2020a). Because temperature has a deterministic effect on properties and structure of stainless steels, this classification based on their structure was made at room temperature. The PH-SS are a highly specialized group of the stainless steels and they have increasingly important in different application areas such as industry, space technology, defense technology, etc. because of their superior properties such as high strength, good ductility, excellent corrosion resistance and ease of fabrication (Smith., 1993).

Many studies on the determination of the properties of PH-SSs are available in the literature (Antony, 1963; Slunder et al., 1967; Ardell, 1985; Hsiao et al., 2002; Pinga et al., 2005; Veljkovic and Gozzi, 2006; Wang et al., 2006; Xu and Yu 2008; Mirzadeh and Najafizadeh 2009; Peng et al., 2015). In these studies, it was reported that PH-SS were divided into three general categories: martensitic (e.g. 15-5PH, 17-4PH, etc.), austenitic and semi-austenitic (e.g. 15-7PH, 17-7PH, etc.). Additionally, it was reported that the martensitic $\mathrm{PH}$ alloys which are fully martensitic at room temperature is a relatively soft, low-carbon (less than $0.05 \%$ ) martensite contrary to the higher carbon available in the martensitic SS. This situation is proof that PH-SSs are technologically more useful than traditional SSs. The PH-SS alloys could considered as ideal structure materials for power plants because of they have a perfect combination of good mechanical properties. (Murayama et al., 1999). Furthermore, PH-SSs can be widely used in nuclear technology, space technologies, protection technologies, energy technologies, accelerators and detector-radiation technologies due to its cubic surface centered lattice structure, easy shaping, good weldability and high oxidation resistance. Therefore, PH-SSs, which are increasing of use with the advancement of technology, is more heterogeneous than structural steels, and because it is an undiscovered world in many respects, they needs to be investigated for many application areas because of their unique properties. Increasing of these investigations will provide a better understanding of the basic properties of the stainless steel examined, discover the advantages, and provide information on how to use it in which field of application.

There are no studies in the literature related to particle radiation investigations, indicating usability in nuclear technology, of PH-SSs that have aforementioned superior properties. Therefore, in this study, it has been aimed to determine whether PH-SSs could be used as energetic particle shields in nuclear applications in order to expand the application areas of these important materials. For this purpose, some important particle-matter interaction parameters that give the shielding capacity of materials that are shields by slowing and/or stopping the energetic particles such as proton, alpha, electron and neutron were calculated. These parameters are the total stopping powers $(S ; d E / d x$; $\mathrm{MeV} / \mathrm{cm})$ with its sub-interactions, range $(R ; \mu \mathrm{m})$ for each charged particles and fast neutron removal cross-section (FNRCS; $\mathrm{cm}^{-1}$ ) for neutron. There are many studies about these important parameters in the literature (Kaplan, 1989; Kabadayi and Gumus 2001; El-Khayatt, 2010; El-Khayatt and Akkurt, 

Charged Particle Radiation

2013; Kurudirek et al., 2014; Kurudirek, 2016; Babu et al., 2018; Ersundu et al., 2018; Issa et al., 2018; Alim et al., 2020b). According to this researches, these parameters are dependent on both the types and kinetic energy of particles and the chemical composition of materials. Additionally, it was reported that these parameters provides important knowledge about the particle shielding capacities of materials interacting with particles and can be used in many application areas such as medicine, nuclear power plants, planning of new nuclear shielding materials, etc. Therefore, knowing these parameters is the most important tool to be used in the selection of the material with the highest shielding properties from a certain class of material with superior properties in terms of particle radiation. Hence, in this study, the stopping power and range results of four different PH-SSs were performed in the energy range of 0.01$20 \mathrm{MeV}$ using SRIM Monte Carlo software (Ziegler et al., 2010) for proton and alpha particles and ESTAR NIST Standard References Databases (Berger et al, 1998; https://physics.nist.gov/PhysRefData/Star/Text/method.html) for electrons. Furthermore, the FNRCS values of present materials were calculated using Phy -X / PSD (Photon Shielding and Dosimetry) (Şakar et al., 2020) software. These investigated parameters were also calculated for three shielding concretes (steel-magnetite (SM), ordinary (OC) and steel-scrap (SS) concretes) that are used as protective materials in nuclear applications (Bashter, 1997) in order to make a significant assessment about usefulness as shielding material of PH-SSs under examination. Additionally, all results obtained were evaluated both as a function of particle kinetic energy and in terms of chemical structure of present PH-SSs together with the results obtained of compared concretes.

\section{MATERIALS AND METHODS}

Particles with positive charge, such as proton and alpha with high kinetic energy, lose their energy primarily by Coulomb interactions with electrons in the orbitals of matter. However, another possible interaction is the Rutherford scattering or alpha-particle induced reaction that occurs with the atomic nucleus. After entering any medium, the charged particle encounters many electrons and interacts with them simultaneously. In such an encounter, electrons are subjected to a force due to charged particles entering the medium. As a result of the interaction of the charged particle with the target material electrons, excitation or ionization of the electrons may occur, depending on the particle energy. These heavy charged particles generally lose their energy through processes called as electronic and nuclear. Unlike heavily charged particles, electrons lose energy through collision or radiative processes as they pass through matter. Like other positively charged particles, electrons often interact simultaneously with the target material electrons. In this case, since the mass of the two particles interacting with each other is equal, the electrons constantly change direction in the material. This causes electrons to travel longer than other positive and highly charged particles in matter. For the reasons described above, the distances that the positive and negative charge particles can take until the material is stopped are called the range and the projected range, respectively. In addition, the total path taken by electrons in the material is called the CSDA (Continuous Slowing Down Approximation) range. Furthermore, while the stopping power $(S ; d E / d x ; \mathrm{MeV} / \mathrm{cm})$ is defined as the energy lost per unit length during penetrating inside the material, the range $(R ; \mu \mathrm{m})$ is defined as the average value of depth in which a charged particle penetrates through the material until it has completely lost its kinetic energy.

The Bethe-Bloch (BB) formulas are used to calculate the stopping power $(S ; \mathrm{dE} / \mathrm{dx} ; \mathrm{MeV} / \mathrm{cm})$ of any material for electrons and positively charged particles (proton, alpha, etc.). This equation applies to electrons and positively charged particles as in Eqs. 1 and 2, respectively (Tsoulfanidis, 2010). 
$S_{e^{-}}=\frac{d E}{d x}=K\left\{\ln \left(\frac{\beta \gamma \sqrt{\gamma-1}}{I} m c^{2}\right)+\frac{1}{2 \gamma^{2}}\left[\frac{(\gamma-1)^{2}}{8}+1-\left(\gamma^{2}+2 \gamma-1\right) \ln 2\right]\right\} \quad$ for electrons

$S_{p^{+}}=\frac{d E}{d x}=K\left[\ln \left(\frac{2 m c^{2}}{I} \beta^{2} \gamma^{2}\right)-\beta^{2}\right] \quad$ for positivelych $\arg$ ed particles

In these equations, $S_{e^{-}}$and $S_{p^{+}}$are the stopping powers of materials for electrons and positively charged particles, respectively. $m c^{2}$ is the rest mass energy of the electron $\left(m c^{2}=0.511 \mathrm{MeV}\right)$ and $I$ is the mean excitation potential of the material. $K, \gamma$ and $\beta$ are calculated by using following formulas:

$\gamma=\frac{T+M c^{2}}{M c^{2}}=\frac{1}{\sqrt{1-\beta^{2}}}$

$K=4 \pi r_{0}^{2} z^{2} \frac{m c^{2}}{\beta^{2}} N Z$

In the Eqs. 3 and 4, $T$ is the kinetic energy of charged particle, $M$ is the rest mass of the charged particle $(\mathrm{kg}), \quad c$ is the speed of light in vacuum, $r_{0}$ is the classical electron radius ( $\left.r_{0}=e^{2} / m c^{2}=2.818 \times 10^{-15} \mathrm{~m}\right), z$ is the charge of the incident particle $\left(z=1\right.$ for $\mathrm{e}^{-}$and proton; $z=2$ for alpha particle) and $Z$ is the atomic number of material. $N$ and $\beta$ are given by Eqs. 5 and 6.

$N=\rho\left(N_{A} / A\right)$

$\beta=v / c$

where, $\rho$ is the density of materials, $A$ is the atomic weight of material, $N_{A}$ is the Avogadro number and $v$ is the velocity of charged particles.

The total stopping power (denoted as $S_{\text {material }}$ ) value of a complex material consisting of more than one element is calculated as follows.

$S_{\text {material }}=\left(\frac{d E}{d x}\right)_{\text {Total }}=\sum_{i} w_{i}\left(\frac{d E}{d x}\right)_{i}$

where $w_{i}$ and $(d E / d x)_{i}$ are the weight fraction and stopping power of the $i^{\text {th }}$ constitute element in material, respectively.

The stopping powers of material for charged particles are divided into two groups. While the groups for electrons are collision and radiative stopping powers (CSP and RSP), the groups for proton and alpha particles are electronic and nuclear stopping powers (ESP and NSP). Additionally, the $S_{\text {material }}$ is sum of the two groups for each charged particles. Hence, the can be presented for electrons and positively charged particles (like proton and alpha) can be presented by Eqs. 8 and 9, respectively.

$S_{\text {material }}=\left(\frac{d E}{d x}\right)_{\text {Total }}=\left(\frac{d E}{d x}\right)_{\text {Col. }}+\left(\frac{d E}{d x}\right)_{\text {Radi. }} \quad$ for electrons

$S_{\text {material }}=\left(\frac{d E}{d x}\right)_{\text {Total }}=\left(\frac{d E}{d x}\right)_{\text {Elec. }}+\left(\frac{d E}{d x}\right)_{\text {Nucl. }} \quad$ for proton and alpha particles

The range values $(R)$ of materials for any charged particles can be calculated by using the $S_{\text {material }}$ values and are given by Eq. 10 . 
$R=\int_{0}^{E} \frac{d E}{(d E / d x)_{\text {Material }}}=\int_{0}^{E} \frac{d E}{S_{\text {material }}}$

The fast neutron removal cross-section FNRCS $\left(\sum_{R} ; \mathrm{cm}^{-1}\right)$ values of the materials can be calculated with the following equation (Wood, 2013; Sakar et al., 2019):

$\sum_{R}=\sum_{i} \rho_{i}\left(\Sigma_{R} / \rho\right)_{i}$

where $\left(\Sigma_{R} / \rho\right)_{i}$ is the mass removal cross-section of the $i^{\text {th }}$ constituent element in material, $\rho_{i}$ is the partial density of the material and can be obtain from Eq. 12.

$\rho_{i}=w_{i} \rho$

where $\rho$ is the density of material and $w_{i}$ is the weight fraction of the $i^{\text {th }}$ constituent element in material (Alim et al, 2020b).

\section{RESULTS AND DISCUSSION}

The precipitation hardening stainless steels (PH-SSs) under examination in this study are martensitic 15-5PH, semi-austenitic 15-7PH, martensitic 17-4PH and semi-austenitic 17-7PH. The some important properties of present PH-SSs is given in Table 1.

Table 1. The some important properties of present PH-SSs.

\begin{tabular}{|c|c|c|c|c|}
\hline \multirow{2}{*}{ Properties } & \multicolumn{4}{|c|}{ PH-SSs } \\
\hline & 15-5 PH & 15-7 PH & 17-4 PH & 17-7 PH \\
\hline Density $\left(\right.$ g.cm $\left.{ }^{-3}\right)$ & 7.8 & 7.81 & 7.82 & 7.81 \\
\hline \multirow{10}{*}{ Chemical Composition (Wt. \%) } & C: $0.06 \%$ & C: $0.07 \%$ & C: $0.06 \%$ & C: $0.07 \%$ \\
\hline & Si: $0.09 \%$ & $\mathrm{Al}: 1.00 \%$ & Si: $0.40 \%$ & $\mathrm{Al}: 1.15 \%$ \\
\hline & P: $0.035 \%$ & Si: $0.09 \%$ & P: $0.030 \%$ & Si: $0.40 \%$ \\
\hline & S: $0.025 \%$ & P: $0.035 \%$ & S: $0.025 \%$ & P: $0.030 \%$ \\
\hline & Cr: $15.00 \%$ & Cr: $15.00 \%$ & Cr: $17.00 \%$ & S: $0.025 \%$ \\
\hline & Mn: $0.70 \%$ & Mn: $0.09 \%$ & Mn: $0.70 \%$ & Cr: $17.00 \%$ \\
\hline & Fe: $75.29 \%$ & Fe: $74.465 \%$ & Fe: $77.485 \%$ & Mn: $0.70 \%$ \\
\hline & Ni: $5.00 \%$ & Ni: $7.00 \%$ & Ni: $4.00 \%$ & Fe: $73.625 \%$ \\
\hline & $\mathrm{Cu}: 3.50 \%$ & Mo: $2.25 \%$ & $\mathrm{Nb}: 0.30 \%$ & Ni: $7.00 \%$ \\
\hline & $\mathrm{Nb}: 0.30 \%$ & & Ni: $10 \%$ & \\
\hline Electrical resistivity ( $\mu . \Omega . \mathrm{cm})$ & $77-80$ & $80-84$ & $70-80$ & $80-85$ \\
\hline Melting point $\left({ }^{0} \mathrm{C}\right)$ & $1404-1440$ & $1400-1450$ & $1400-1440$ & 1435 \\
\hline $\begin{array}{l}\text { Thermal conductivity at } 260{ }^{\circ} \mathrm{C} \\
\left(\mathrm{W} \cdot \mathrm{m}^{-1} \cdot \mathrm{K}^{-1}\right)\end{array}$ & 17.90 & 18.60 & 19.50 & 18.50 \\
\hline $\begin{array}{l}\text { Coefficient of thermal expansion at } \\
\text { between } 20{ }^{0} \mathrm{C} \text { and } 100{ }^{0} \mathrm{C}\left(\times 10^{-6}{ }^{0} \mathrm{C}^{-1}\right)\end{array}$ & 10.80 & 14.40 & 11.90 & 15.30 \\
\hline Elastic Modulus at $20{ }^{\circ} \mathrm{C}(\mathrm{GPa})$ & 196 & 200 & 197 & 204 \\
\hline Tensile strength (MPa) & $1010-1140$ & $1000-1020$ & $1050-1150$ & $1020-1550$ \\
\hline
\end{tabular}


In this study, the shielding performances of PH-SSs investigated for radiations of different particles were presented in detail. The investigated parameters are the stopping powers (TSP, ESP and NSP for proton and alpha particles and TSP, CSP and RSP for electrons), range values $(R)$ for charged particles (proton, alpha and electron) and FNRCS for neutrons.

The total stopping power (TSP) quantity, which indicates the probability that energetic particles can interact with the substance, is derived from the sum of different interactions, depending on whether the charge is positive or negative. These interactions are electronic and nuclear interactions for positively charged particles such as protons and alpha, and collision and radiative interactions for electrons. In this study, in addition to total stopping powers of materials for energetic charged particles (proton, alpha and electron), variations of the previously mentioned interaction parameters are graphically presented as a function of kinetic energies of the particles.

For protons having kinetic energy between $0.01 \mathrm{MeV}$ and $20 \mathrm{MeV}$, the changes in the ESP, NSP, TSP and range $(R)$ values of both PH-SSs and comparison shielding concretes (SS, SM and OC) are shown in Fig. 1(a)-(d). From Fig 1(a) and (b), it is seen that PH-SSs have higher electronic and nuclear stopping power values than comparison shielding concretes in the whole energy range. In this energy range examined, it is clearly seen from this graphs that electronic interactions are much more dominant than nuclear interactions. For example, the ratio of ESP to NSP is $1.64 \times 10^{3}$ at $3 \mathrm{MeV}$ kinetic energy for 15-5 PH. Therefore, nuclear interactions can be ignored in the calculation of the total amount of stopping power. Variations of TSP values versus kinetic energy of the protons (Fig. 1(c)) support this situation and have almost the same variation curves as ESP for all investigated materials. Additionally, it is seen from Fig. 1(c) that PH-SSs have higher TSP values in the energy range 0.01-20 MeV than OC, SS and $\mathrm{SM}$ concretes. Because the elemental compositions of the PH-SSs are very close to each other, there is no significant differences in the TSP values of these stainless steels. It is known that the materials that have high TSP values have low $R$ and mean free path (MFP) values and that these materials can be used as good protective materials for particle radiation applications. It is shown in Fig. 1(d) that PH-SSs can stop protons with high kinetic energy at shorter distances. For example, the thickness required to stop protons at $20 \mathrm{MeV}$ energy is averagely $853 \mu \mathrm{m}$ for PH-SSs, while 1270, 1590 and $2310 \mu \mathrm{m}$ for SM, SS and OC, respectively. This result are proof that the PH-SSs investigated have better shielding capacities than comparison concretes for proton radiation. 

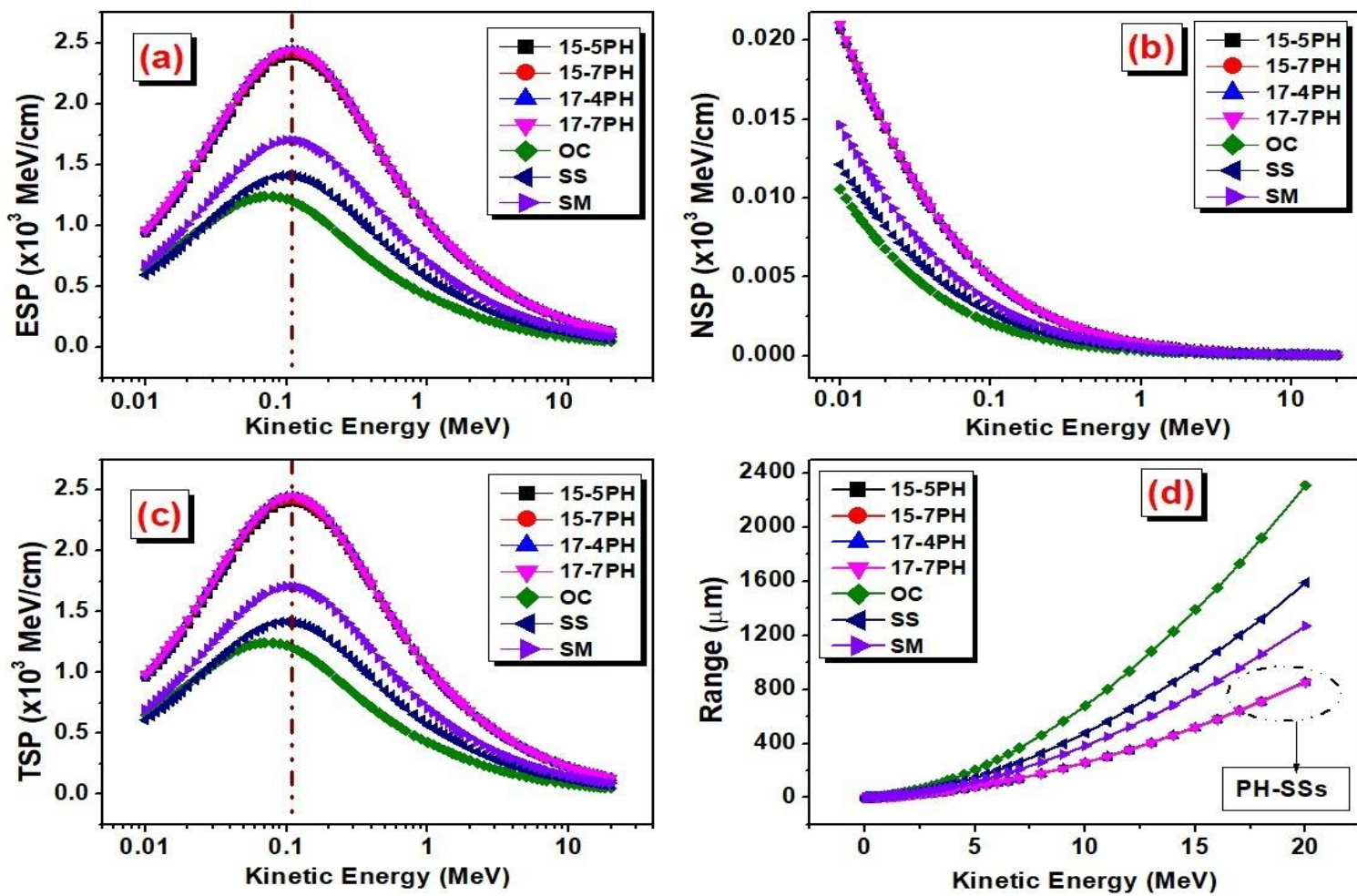

Figure 1. The variations of stopping powers (a) Electronic b) Nuclear c) Total) and e) range values for protons versus kinetic energy.

Because alpha particles have a positive charge like protons, they are evaluated in the same group in the Bethe-Block formula and the mechanisms of interaction with the materials are the same. These two particles are separated from each other only by their atomic mass and electrical charge. Therefore, alpha particles lose their energy through electronic and nuclear interactions as like protons. Since the mass of the alpha particles have higher about four times than protons, at any kinetic energy, the velocities of alpha particles are evenly lower than protons. Relatively low particle speed means less stopping power and range. When Fig 1(c) and Fig 2(c) are evaluated together, it is clearly seen that the total stopping power of the any materials at the same energy value examined for protons are higher than that of the alpha particles. As with the protons, the electronic (Fig 2(a)) and nuclear (Fig 2(b)) and therefore total stopping power (Fig 2(c)) values of the PH-SSs are higher than SS, SM and OC concretes. In addition to the stopping power results of alpha particles, the variations of the range values versus kinetic energy are presented in Fig 2(d). This graph shows that $\mathrm{PH}$ group alloys have lower range values than other compared concretes. When Fig 2(d) and Fig 1(d) are evaluated together, it is clearly seen that the R values for alpha particles are lower than corresponding values of each investigated materials at same kinetic energy values for protons. It is inferred from these results that the PHs examined for alpha radiation, parallel to the results obtained for protons, are more suitable for nuclear applications because of they perform higher than comparison concretes. When Figs. 1(a), (c) and Figs. 2(a), (c) were evaluated together, the maximum $\mathrm{S}$ values for protons and alpha particles were observed at about 0.1 and $1 \mathrm{MeV}$, respectively. 

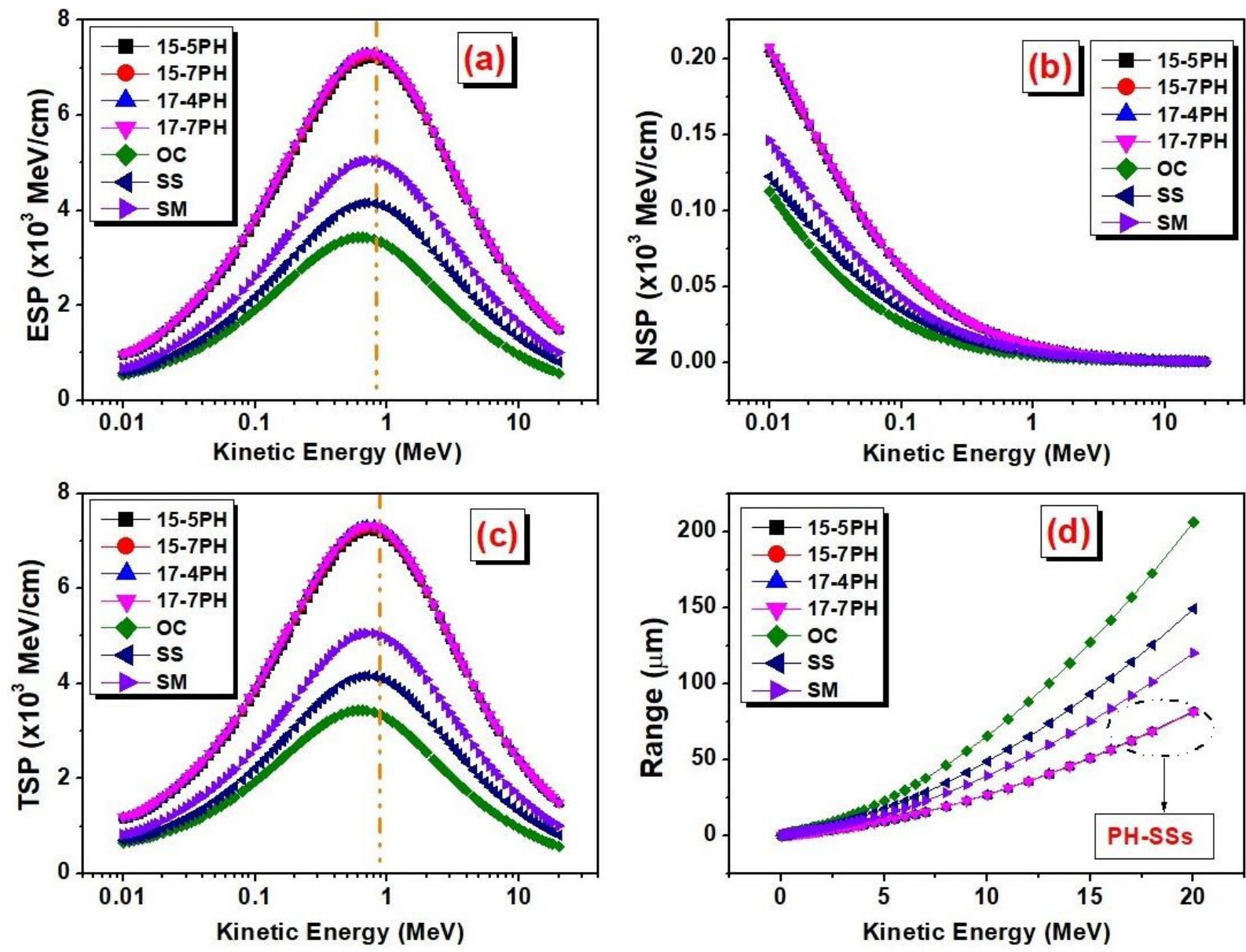

Figure 2. Variations of stopping powers (a) Electronic b) Nuclear c) Total) and e) range values for alpha particles versus kinetic energy.

In addition to proton and alpha particles, it is also important to know the interactions of electrons on matter. When electrons come to the material, there are two processes called collision and radiative. The total interaction probability is generally controlled by the collision process in the low energy region, while the collision and radiative processes contribute together in the high energy region ( $E_{\text {electron }}>$ $1 \mathrm{MeV}$ ). The energy-dependent changes of the CSP/RSP ratios are given in Fig 3. It is understood that CSP/RSP ratios decreases with increasing kinetic energy of electrons, that is, the contributions of RSP interactions to TSP values the contribution of RSP interactions to TSP values increase as a function of the increasing kinetic energy of electrons.
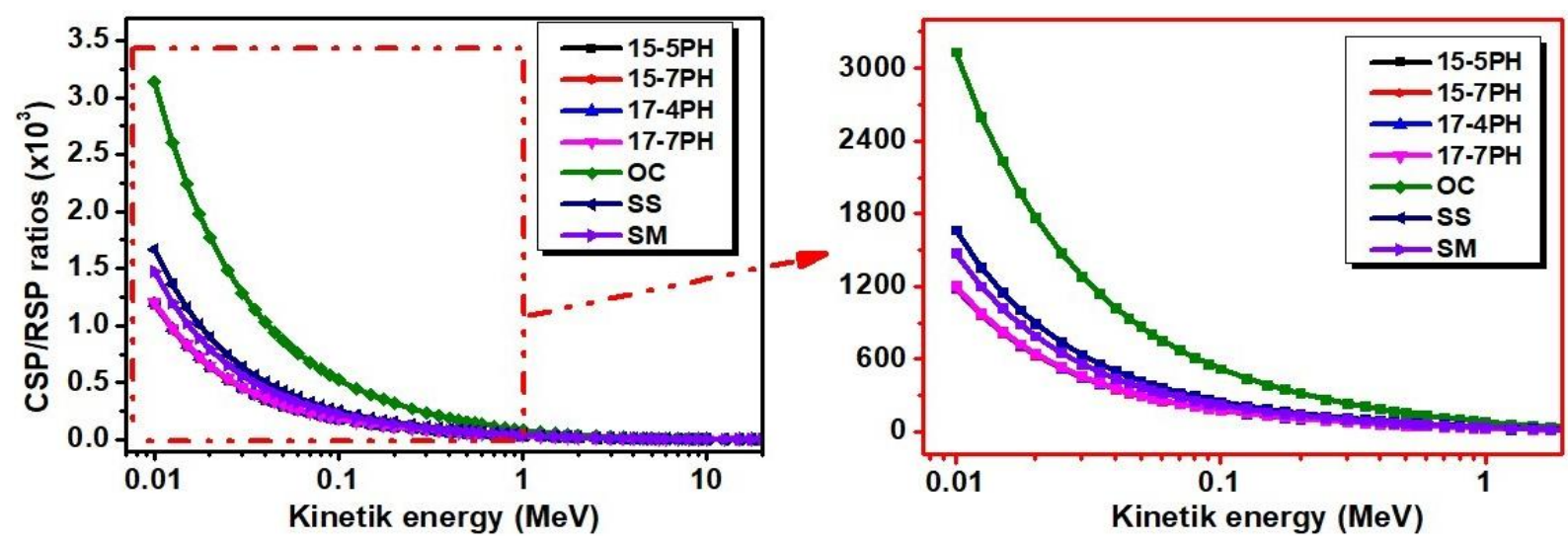

Figure 3. The changes of CSP/RSP ratios versus kinetic energy of electrons. 
In Figs. 4(a)-(c), the changes of collision, radiative and total stopping power of materials investigated for electrons are presented, respectively. It can be seen from these figures that the PH-SSs are much more likely to interact with electrons than other concretes. In the energy range of 0.015-20 $\mathrm{MeV}$, the decreasing order of stopping power values for electrons was obtained as $\mathrm{PH}-\mathrm{SSs}>\mathrm{SM}>\mathrm{SS}>$ OC. The results of the range, which is the total path that electrons will travel as a result of collision of electrons in the material, are given in Fig 4(d). Up to $1 \mathrm{MeV}$ kinetic energy, the penetration of electrons is very low, so the range values are almost zero regardless of the material composition. However, after this energy value, the range values have a rapid increase in parallel with the increased energy for all materials. From the figure, the fastest increase was observed in the OC sample while the lowest increase was observed in the PH-SSs. This small increments in the range of the PH-SSs is the evidence that these stainless steels require less material thickness than other concretes for shielding in terms of high energetic electrons.

Finally, the present PH-SSs were investigated in terms of fast neutron removal cross section. Because the neutrons are electrically neutral particles, there is no possibility of coulombic interaction of these particles with electrons or protons contained in the material. These particles lose their energy by elastic or non-elastic collisions. Because all neutrons are emitted as fast neutrons, it is important to know the FNRCS values of the materials for design of new type shielding materials. The graphical representation of both FNRCS values of PH-SSs and other standard concretes is given in Fig. 5. It can be seen from the graph that the FNRCS values of PH-SSs are very close to each other and are higher than SM, SS and OC concretes. The results clearly show that PH-SSs can be regarded as suitable protective materials for fast neutrons.
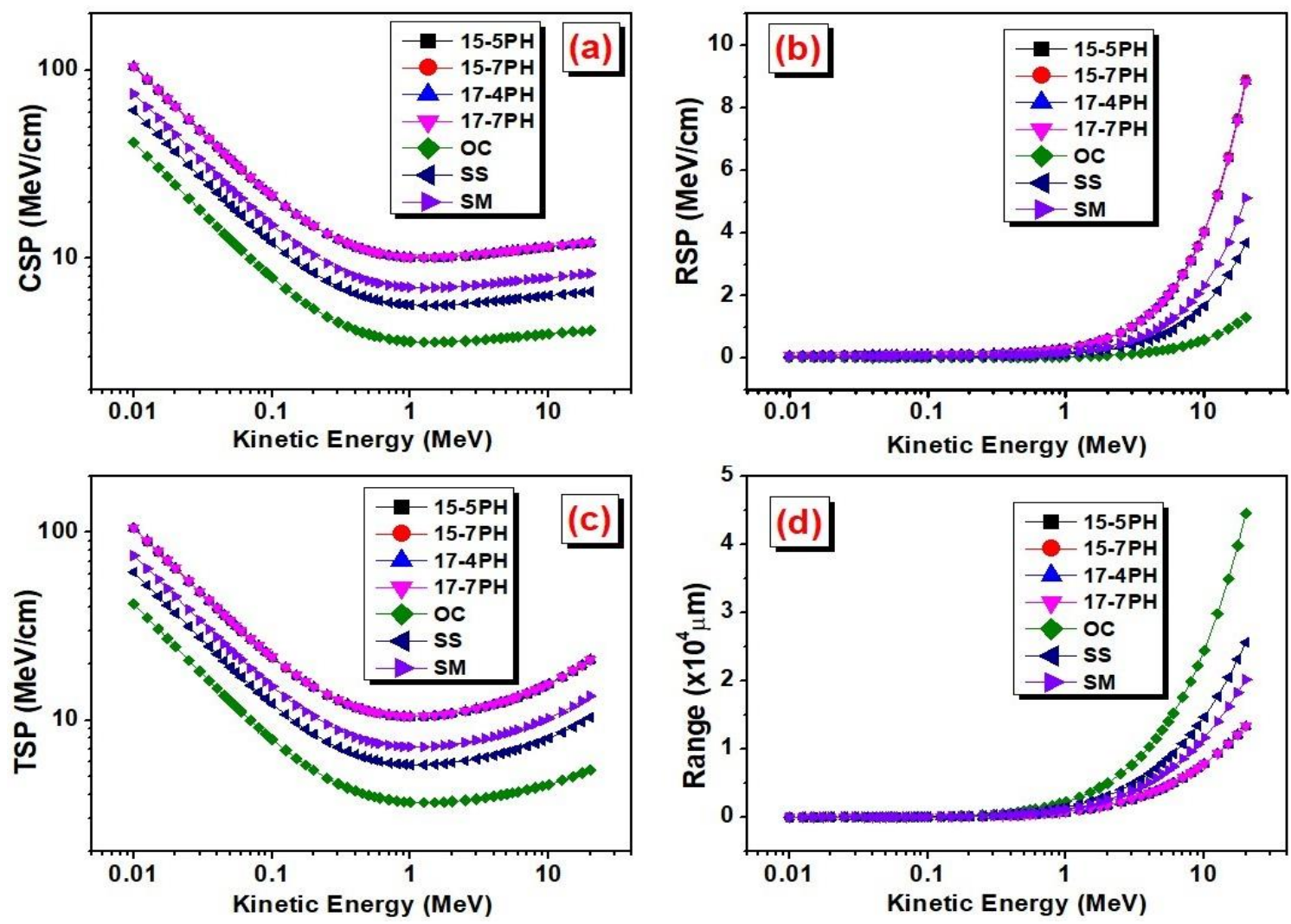

Figure 4. Variations of stopping powers (a) Collision b) Radiative c) Total) and e) range values for electrons versus kinetic energy. 
Consequently, as can be seen from the all figures given, when the all results obtained are evaluated together, it was seen that the calculated parameters for PH-SSs examined are very close to each other. When the PH-SSs examined are evaluated according to the phase structures considering this result obtained, it was concluded that the calculated parameters were almost independent of the phase structure for the PH-SSs examined. For example, although 17-4PH and 17-7PH materials have different phase structures (martensitic for $17-4 \mathrm{PH}$ and semi-austenitic for $17-7 \mathrm{PH}$ ), all parameters examined in this study for this materials were found to be almost identical.

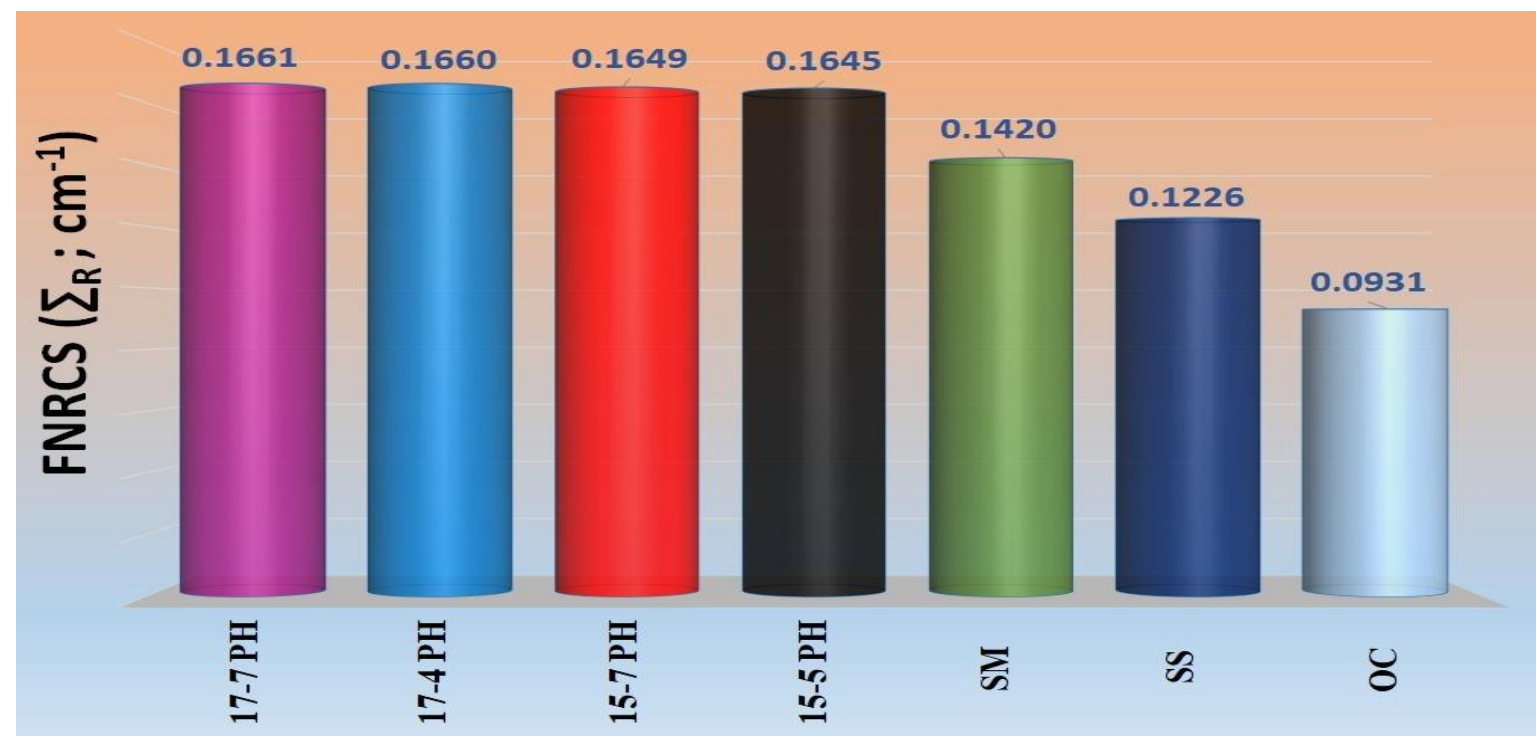

Figure 5. The values of fast neutron removal cross-section of the investigated materials.

\section{CONCLUSION}

In this study, protective capacities of precipitation hardening stainless steels (PH-SSs) in terms of proton, alpha, electron and neutron particle radiation were investigated. For this purpose, the stopping powers and spacing calculations for the charged particle radiation of four different stainless steels (17$7 \mathrm{PH}, 17-4 \mathrm{PH}, 15-7 \mathrm{PH}$ and $15-5 \mathrm{PH})$ were calculated over a wide energy range. The sub-interaction groups (electronic and nuclear for positive charged particles and collision and radiative for electrons) constituting the total stopping power were evaluated separately. In addition, FNRCS values of these alloys were calculated. The results obtained were compared with the standard shielding materials such as SS, SM and OC concretes. Because the contents of the PH-SSs were close to each other, they were found to have similar shielding characteristics throughout the entire energy range. From the results obtained, it was found that PH-SSs have quite high stopping power and much smaller range values for all charged particle radiation types compared to concretes. In addition, it was obtained that PH-SSs have an average of $30 \%$ higher FNRCS than comparison concretes. From the study, it was found that PH-SSs exhibited very good shielding properties for all particle radiation (charged and un-charged) over a wide energy range. Furthermore, it was observed that the all results obtained for PH-SSs investigated were almost independent of the phase structure such as martensitic, austenitic and semi-austenitic. Consequently, due to their perfect properties such as high densities, high melting points reaching $1450^{\circ} \mathrm{C}$ and superior protection properties, PH-SSs can be used as an alternative material in areas where particle radiation safety is required. 


\section{REFERENCES}

Alım B, Şakar E, Baltakesmez A, Han İ, Sayyed M, Demir L. 2020a. Experimental investigation of radiation shielding performances of some important AISI-coded stainless steels Part I. Radiation Physics and Chemistry, 166: 108455.

Alım B, Şakar E, Han İ, Sayyed M. 2020b. Evaluation the gamma, charged particle and fast neutron shielding performances of some important AISI-coded stainless steels: Part II. Radiation Physics and Chemistry, 166: 108454.

Antony KC. 1963. Aging Reactions in Precipitation Hardenable Stainless Steel. Journal of Metals, 15 (12): $922-$ 927.

Ardell AJ. 1985. Precipitation hardening. Metallurgical and Materials Transactions A, 16: 2131-2165.

Babu SR, Badiger NM, Karidurgannavar MY, Varghese JG. 2018. Measurement of mass stopping power of chitosan polymer loaded with $\mathrm{TiO} 2$ for relativistic electron interaction. Radiation Physics and Chemistry, 145: $1-4$.

Bashter II. 1997. Calculation of radiation attenuation coefficients for shielding concretes. Annals of Nuclear Energy, 24 (17): 1389-1401.

El-Khayatt AM, Akkurt I. 2013. Photon interaction, energy absorption and neutron removal cross section of concrete including marble. Annals of Nuclear Energy, 60: 8-14.

El-Khayatt AM. 2010. Calculation of fast neutron removal cross-sections for some compounds and materials. Annals of Nuclear Energy 37: 218-222.

Ersundu AE, Buyukyildiz M, Ersundu MC, Sakar E, Kurudirek M. 2018. The heavy metal oxide glasses within the WO3-MoO3-TeO2 system to investigate the shielding properties of radiation applications. Progress in Nuclear Energy, 104: 280-287.

Hsiao CN, Chiou CS, Yang JR. 2002. Aging reactions in a 17-4 PH stainless steel. Materials Chemistry and Physics, 74: 134-142

https://physics.nist.gov/PhysRefData/Star/Text/method.html.

Issa SAM, Saddeek YB, Tekin HO, Sayyed MI, Shaaban KS. 2018. Investigations of radiation shielding using Monte Carlo method and elastic properties of PbO-SiO2-B2O3-Na2O glasses. Current Applied Physics, 18: 717-727.

Kabadayi O, Gumus H. 2001. Calculation of average projected range and range straggling of charged particles in solids. Radiation Physics and Chemistry, 60: 25-31.

Kaplan MF. 1989. Concrete radiation shielding. John Wiley \& Sons, New York.

Kurudirek M, El-Khayatt AM, Gerward L. 2014. Remarks on the extension and validity of an empirical formula for the fast-neutron removal cross-section: The effective atomic weight. Annals of Nuclear Energy 70, 230232.

Kurudirek M. 2016. Effective atomic number, energy loss and radiation damage studies in some materials commonly used in nuclear applications for heavy charged particles such as $\mathrm{H}, \mathrm{C}, \mathrm{Mg}, \mathrm{Fe}, \mathrm{Te}, \mathrm{Pb}$ and $\mathrm{U}$. Radiation Physics and Chemistry, 122: 15-23.

Mirzadeh H, Najafizadeh A. 2009. Aging kinetics of 17-4 PH stainless steel. Materials Chemistry and Physics 116: 119-124.

Murayama M, Hono K, Katayama Y. 1999. Microstructural evolution in a 17-4 PH stainless steel after aging at $400{ }^{\circ} \mathrm{C}$ Metallurgical and Materials Transactions A, 30 (2): 345-353.

Pinga DH, Ohnumaa M, Hirakawab Y, Kadoyab Y, Honoa K. 2005. Microstructural evolution in $13 \mathrm{Cr}-8 \mathrm{Ni}-$ 2.5Mo-2 Al martensitic precipitation-hardened stainless steel Materials Science and Engineering A, 394: 285-295

Slunder CJ, Hoenie AF, Hall AM. 1967. Thermal and Mechanical Treatment for Precipitation-Hardening Stainless Steels. NASA SP-5089, published by NASA, Washington DC, 192 pages.

Smith WF. 1993. Structure and Properties of Engineering Alloys. McGraw-Hill, Inc. 
Sakar E, Buyukyildlz M, Alim B, Sakar BC, Kurudirek M. 2019. Leaded brass alloys for gamma-ray shielding applications. Radiation Physics and Chemistry, 159, 64-69.

Şakar E, Özpolat ÖF, Alım B, Sayyed M, Kurudirek M. 2019. Phy-X/PSD: Development of a user friendly online software for calculation of parameters relevant to radiation shielding and dosimetry. Radiation Physics and Chemistry, 166: 108496.

Tsoulfanidis N. 2010. Measurement and detection of radiation. CRC press.

Veljkovic M, Gozzi J. 2006. Use of Duplex Stainless Steel in Economic Design of a Pressure Vessel. ASME. J. Pressure Vessel Technology, 129 (1):155-161.

Wang SC, Starink MJ, Gao N. 2006. Precipitation hardening in Al-Cu-Mg alloys revisited Scripta Materialia, 54: $287-291$.

Wood J. 2013. Computational methods in reactor shielding. Pergamon, 450 pages.

Xin GP, Xian GZ, Xiao GH, Zhen GW, Hua GL. 2015. Effect of Aging on Hardening Behavior of 15-5 PH Stainless Steel Journal of Iron and Steel Research, 22 (7): 607-614.

Xu XL, Yu ZW. 2008. Metallurgical analysis on a bending failed pump-shaft made of 17-7PH precipitationhardening stainless steel. Journal of Materials Processing Technology, 198: 254-259.

Ziegler JF, Ziegler MD, Biersack JP. 2010. SRIM - The stopping and range of ions in matter. Nuclear Instruments and Methods in Physics Research Section B: Beam Interactions with Materials and Atoms, 268: 1818-1823. 